\title{
New records including new species of Megaselia Rondani and Triphleba Rondani (Diptera: Phoridae) from Finland
}

\author{
R. Henry L. DISNEY ${ }^{1}$ and Kaj WINQVIST ${ }^{2}$ \\ ${ }^{1}$ Department of Zoology, University of Cambridge, Cambridge CB2 3EJ, England; e-mail: rhld2@hermes.cam.ac.uk \\ ${ }^{2}$ Kastuntie 45 D 36, 20300 Turku, Finland; email: zeitkajw@gmail.com
}

\begin{abstract}
Eleven new records of Phoridae from Finland and eight new species of Megaselia Rondani. M. confusus n. sp., M. eeroi n. sp., M. horrenticauda n. sp., M. kajaaniensis n. sp., M. miroparaphysis n. sp., M. necrubida n. sp., M. turkuensis n. sp., M. utsjokiensis n. sp. plus the hitherto unknown female of Triphleba aequalis (Schmitz) and Triphleba cumsetae n. sp. are presented.
\end{abstract}

Key words: Phoridae, Finland, new species

\section{INTRODUCTION}

Historically, Phoridae has been rather a neglected fly family in Finland though local dipterologists of the 20th century included an interest in Phoridae. Hackman (1980) reported 200 species in his old checklist, and in the updated checklist of Finnish flies Kahanpää (2014) the number of recorded Finnish phorids had risen to 216-226 species, but with some of them being uncertain records. It remains remarkably easy to find unrecorded, including undescribed, phorid species, especially in the northern parts of the country. The total number of Phoridae present in Finland must be substantially higher; especially in the giant genus Megaselia Rondani. Collecting by e.g. author KW was undertaken in order to add to the number of species recorded from Finland.

\section{MATERIAL AND METHODS}

The specimens were collected by netting, in a Malaise trap or a hybrid trap consisting of a funnel with two crossed PVC-panels/boards and with a roof above, in this respect resembling a small-sized malaise. The specimens were preserved in 70\% ethanol. RHLD mounted them on slides in Berlese Fluid (Disney 2001). With the giant genus Megaselia, whose scope has progressively expanded as hundreds of new species have been added, detailed diagnoses of individual species would be almost as long as the descriptions of the species. Instead it is indicated how each runs down in the relevant existing keys (Schmitz \& Delage, 1974, 1981) and Disney (1989), and how they differ from the species of the couplet reached and from subsequent species running to the same couplet.

All the species except Megaselia emarginata (Wood) and Triphleba papillata (Wingate) are determined by Henry Disney and deposited in the University of Cambridge Museum of Zoology (UCMZ). 


\section{Abaristophora arctophila Schmitz, 1927}

Previously known from the Far East of Russia (Kamchatka) and from Sweden.

Material examined. Male, Finland, Lkor, Pelkosenniemi, Kätkäaapa 7453421:3538172, 31 Jul-29 Sep 2015, open bog, J. Salmela leg. (Malaise trap).

\section{Borophaga bennetti Disney, 2010}

Previously known from Scotland, Isle of Man and Hungary.

Material examined. Male, Finland, Lkor, Pelkosenniemi, Kätkäaapa 7453290:3538068, 3 Jun-9 Jul 2015, open bog with springs, J. Salmela leg. (Malaise trap).

\section{Gymnophora Macquart, 1835}

Several new species were obtained, three being from Finland, and were covered by Disney (2017) in a review of the European species.

\section{Megaselia cirriventris Schmitz, 1929}

This Holarctic species is common in Greenland but is also recorded from N-W Russia (Kola Peninsula) and Sweden. The following is the first record for Finland.

Material examined. Male, Finland, Obb: Tervola, Pisavaara, Alalaki, 7348763: 3414247, mossy spring area, 8 Jul-15 Aug 2016, J. Salmela leg, (Malaise trap).

\section{Megaselia confusus n. sp.}

(Figs 1-8)

Diagnosis. (Male). In the keys to British species (Disney 1989) it runs to couplet 133, where neither lead fits. The subsequently described $M$. solii Disney runs to this couplet and is similar, but its hypopygium differs and it has shorter costal cilia and outermost axillary bristles, a longer hair palisade on the mid tibia and half as many differentiated posterodorsal hairs on the hind tibia. In Schmitz \& Delage's (1974) keys to Abteiling V it runs to couplet 29, where neither lead fits.

Male. Frons as Fig. 1 and with very dense but very fine microtrichia. Cheek with 2 bristles and jowl with 2 that are a little longer and more robust. The subglobose postpedicels brown, with many pale spots, but without SPS vesicles. Palps and proboscis as Fig. 2. Thorax brown. Three notopleural bristles and mesopleuron with 5-8 hairs (Fig. 3). Scutellum with an anterior pair of hairs and a posterior pair of bristles. Abdominal tergites brown with moderate hairs that are only a little longer at rear of T6. Venter brown, and with hairs on segments 3-6. Hypopygium as Figs $4-5$, the lobe of the right side of the hypandrium being vestigial. Fore tarsus with posterodorsal hair palisade on segments 1-4 and as Fig. 6. Dorsal hair palisade of mid tibia extends only about 0.4 times its length its length (Fig. 7). Hairs below basal half of hind femur shorter than those of anteroventral row of outer half (Fig. 8). Hind tibia with about two dozen differentiated posterodorsal hairs, without anterodorsals, and spinules of apical combs simple. Wings $1.34 \mathrm{~mm}$ long. Costal index 0.35. Costal ratios 6.3-6.4 : 1.8 : 1. Costal cilia (of section 3) $0.14 \mathrm{~mm}$ long. No hair at base of vein 3. With 2 unequal axillary bristles, the outer being $0.12 \mathrm{~mm}$ long. Sc not reaching R1. Thick veins brownish gray, veins 4-6 gray and 7 very pale. Membrane lightly tinged gray (not evident to naked eye when viewed against a white background). Haltere brown. 


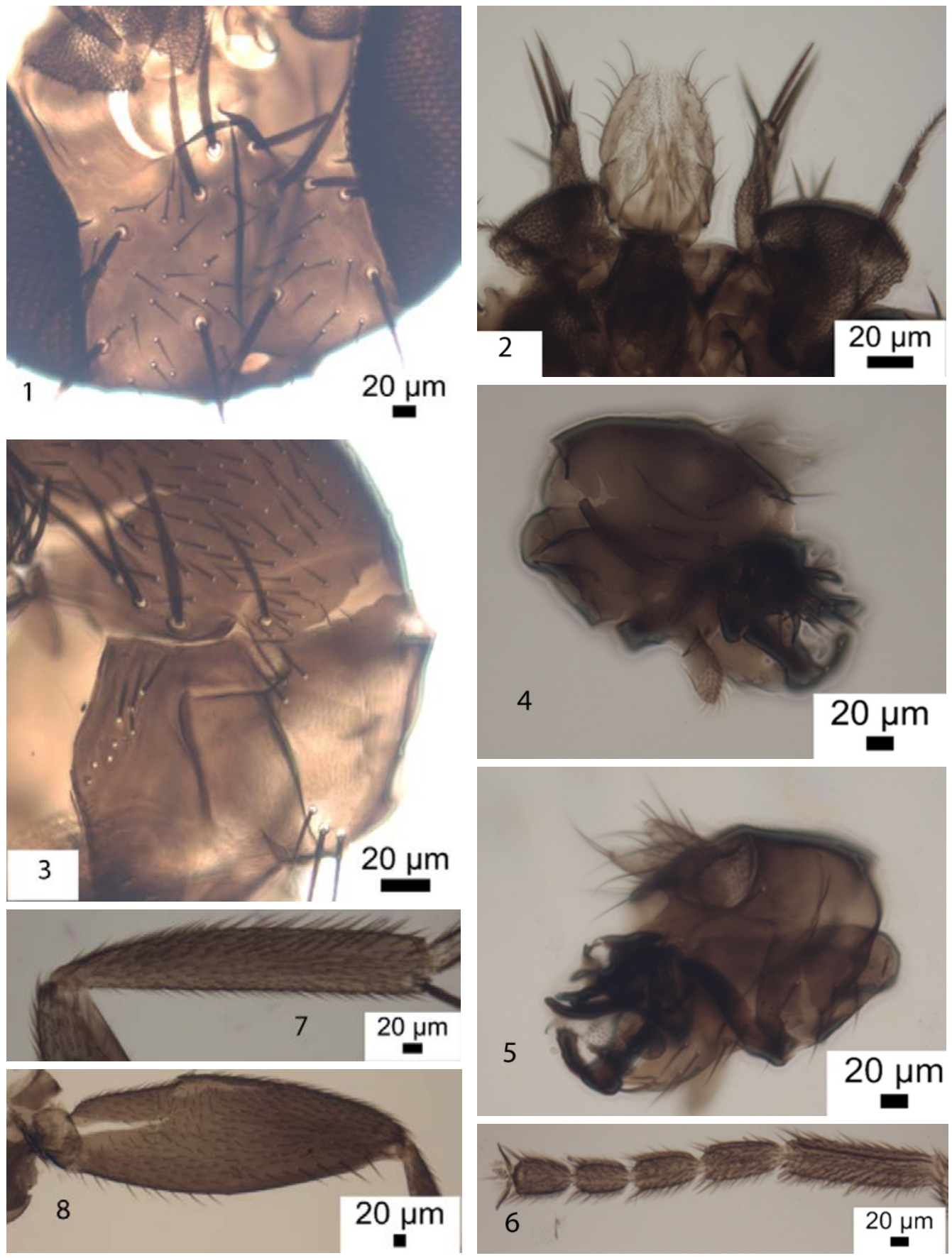

Figs 1-8. Megaselia confuses n. sp. male: 1 - frons; 2 - palps and proboscis; 3 - right thoracic pleura; 4 - left face of hyopopygium; 5 - right face of hypopygium; 6 - front tarsus; 7 - mid tibia; 8 - hind femur. 
Material examined. Holotype male, Finland, Ab: Turku, Satava, Samppa, 67020.32310, roadside, 24 Jun 2016, K. Winqvist leg. (UCMZ, 39-83).

Etymology. Named $M$. confusus because at low magnifications it can be readily confused with several other species.

\section{Megaselia consetigera (Schmitz, 1925)}

The following is the first record for Finland.

Material examined. Male, Finland, Ab: Turku, Ruissalo, 6709:3233, roadside with reeds, 4 Sep 2015, K. Winqvist leg.

\section{Megaselia crassipes (Wood, 1909)}

The following is the first record for Finland.

Material examined. Male, Finland, Ab: Turku, Satava, 67028:32318, birch forest with reeds near sea, 1 Jul 2015, K. Winqvist leg.

\section{Megaselia drakei Disney, 1984}

Previously known from England, Isle of Man, Denmark, France, Germany, Sweden, Switzerland. The following is the first record for Finland.

Material examined. Male, Finland, Ab: Turku, Satava, mixed forest, 67028:32324, 19 Jul 2015. K. Winqvist leg.

Megaselia eeroi Disney, n. sp.

(Figs 9-15)

Diagnosis (male). In the key of Schmitz \& Delage (1974) for Abteilung V it runs to couplet 6 on page 638, to M. divergens (Malloch). However, Borgmeier (1964) incorrectly synonymized $M$. fenestralis (Schmitz) with this species, which was reinstated by Disney (1987). M. divergens is immediately distinguished by its brown anal tube, as well as by other small details such as its shorter costal index. $M$. fenestralis is immediately distinguished by its well developed lobe on the left side of the hypandrium (Fig. 16), the elongated posteroventral lobes of the epandrium (Figs 16-17), and by its wing having a small hair at the base of vein 3 and 2 axillary bristles.

Male. Frons as Fig. 9 and with dense but very fine microtrichia. Cheek with 5 bristles and jowl with 2 that are longer and more robust. Postpedicel as Fig. 10, without SPS vesicles. Palp as Fig 11. Labrum pale and about 0.5 times as wide as a palp. Labella pale and with about a dozen short spinules below each. Thorax brown. Three notopleural bristles and no cleft in front of these. Mesopleuron with only 2-3 hairs. Scutellum with an anterior pair of small hairs and a posterior pair of bristles. Abdominal tergites brown with moderate hairs largely restricted to hind margins. Venter light brownish gray, and with hairs on segments 3-6. Hypopygium as Fig. 12-14. Legs brown but not dark. (Fore tarsal segments $2-5$ missing in type). Dorsal hair palisade of mid tibia extends only about 0.4 times its length. Hind femur as Fig. 15. Hind tibia with 16-18 moderately differentiated posterodorsal hairs, without anterodorsals, and spinules of apical combs simple. Wings very pale and $1.22 \mathrm{~mm}$ long. Costal index 0.38-0.40. Costal ratios $4.3: 1.0: 1$. Costal cilia (of section 3 ) $0.10 \mathrm{~mm}$ long. No hair at base of vein 3 . With 2 axillary bristles, the outer being $0.07 \mathrm{~mm}$ long. Sc not reaching R1. Thick veins pale gray, thin veins 4-6 very pale gray and 7 not evident. Haltere with brown knob.

Material examined. Holotype male, Finland, Ab: Mynämäki, Karjalankylä, 67568:32279, 13 Sep-20 Nov 2012, E. Vesterinen leg. (hybrid trap) (UCZM, 34-186) 
Etymology. For Eero Vesterinen, the collector of the holotype.
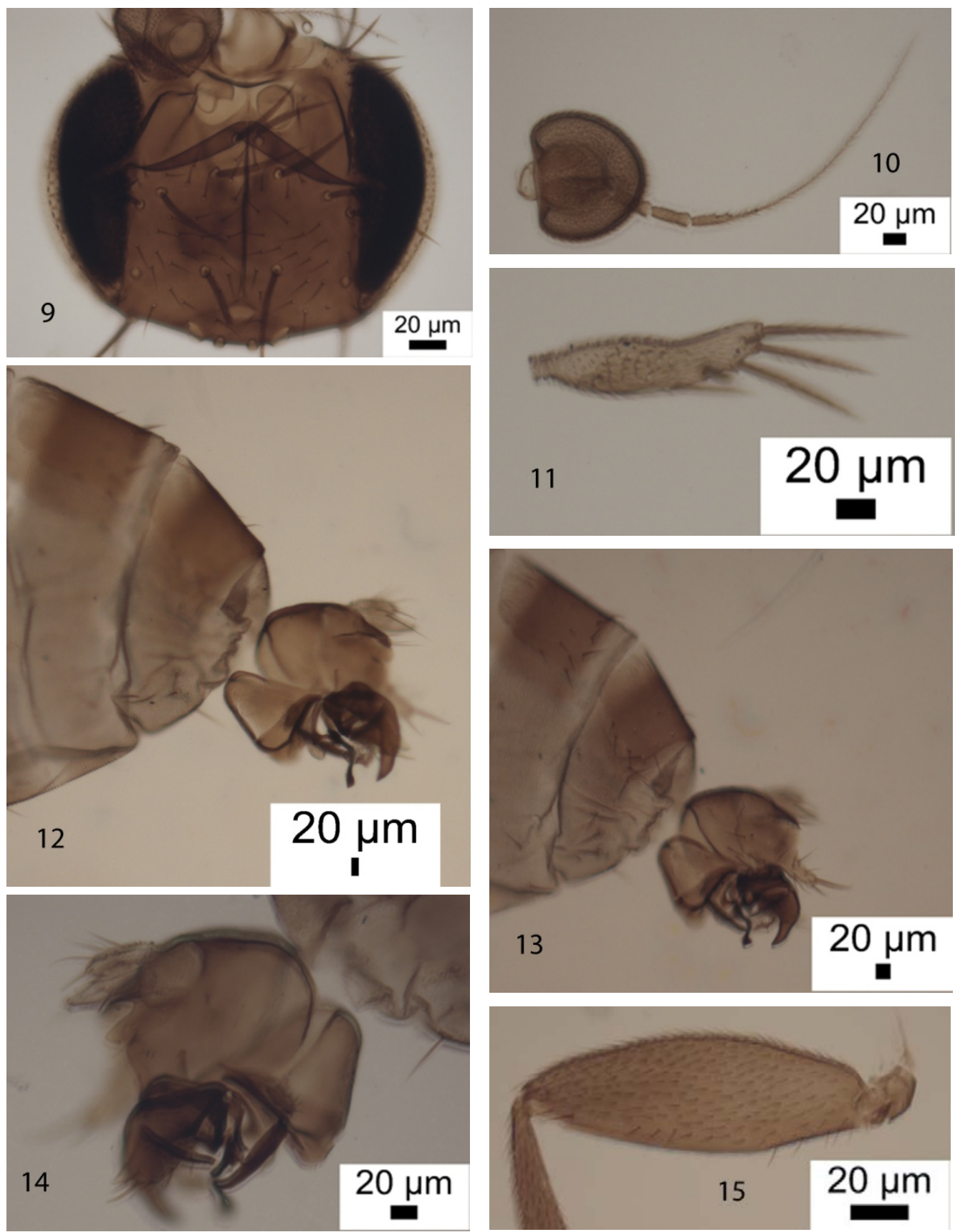

Figs 9-15. Megaselia eeroi n. sp. male: 9 - frons; 10 - postpedicel; 11 - palp; 12-14 - hypopygium; 15 - hind femur. 

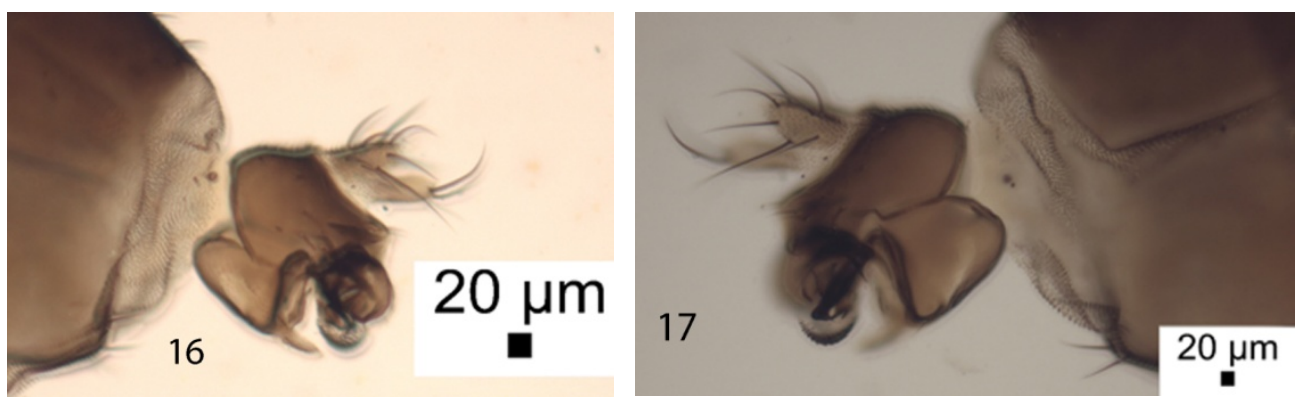

Figs 16-17. Megaselia fenestralis (Schmitz) male hypopygium: 15 - left face; 16 - right face.

\section{Megaselia emarginata (Wood, 1908)}

Previously known from British Isles, Sweden and France to Poland and Portugal and east to Hungary. The first record for Finland.

Material examined. Male: Finland, LkOr: Pelkosenniemi, Kätkäaapa, 7453290:3538068, open bog with springs, 3 Jun-9 Jul 2015, J. Salmela leg. (Malaise trap), K. Winqvist \& A. Haarto det.

\section{Megaselia horrenticauda n. sp.}

(Figs 18-27)

Diagnosis (male). In the key to the males of the British species (Disney 1989) it runs to couplet 161, but as the epandrial hairs are somewhat robust along the lower margins one could take either option. At couplet 162 lead 1 is for M. spinicincta (Wood), whose hypopygium resembles the new species but with a shorter dorsal face to the epandrium (Figs 28-30). In addition it has only two bristles on the notopleuron, a costal index less than 0.5 (Fig. 32) and a posterodorsal hair palisade on segment $1-4$ of the front tarsus (Fig. 31). Taking lead 2 at couplet 162 one proceeds to couplet 187, where the choice is between the vein Sc running to vein 1 or falling just short of it. As the Sc is only just short of vein 1 (Fig. 27), at low magnifications it may appear to join vein 1 . Taking the first option one proceeds to couplet 194, to M. rubella (Schmitz), whose epandrium has fewer and much finer hairs; as does the subsequently described $M$. kanoi Disney that runs to the same point. Taking the second option at couplet 187 one proceeds to couplet 204, where the separation is between a yellow haltere knob or one that is variably darker. The first option leads to couplet 232, lead 2, where one is returned to a complex that all have fewer and weaker epandrial hairs. Taking the second option from couplet 204 one arrives at couplet 388 and M. invernessae Disney, whose epandrial hairs are likewise weaker and fewer. Indeed the hypopygium of the new species is closer to $M$. spinicincta than to any other subsequently described species running to any of the above couplets.

Male. Frons as Fig. 18 and with dense but very fine microtrichia. Cheek with 5-7 fine bristles and jowl with a single very long bristle. Postpedicels as Fig. 19 and without SPS vesicles. Palps yellow, about a third as broad as postpedicel, with 4 bristles and as many hairs. Labrum pale. Labella as Fig. 20. Thorax brown. Three notopleural bristles, but the middle one is the smallest (Fig. 21) and no cleft in front of these. Mesopleuron bare. Scutellum with an anterior pair of small hairs and a posterior pair of bristles. Abdominal tergites brown with numerous hairs that are longest posterolaterally on T6. Venter brown, and with hairs on segments 3-6. Hypopygium as Figs 22-23. Legs yellow apart from brown tip to hind femur. 

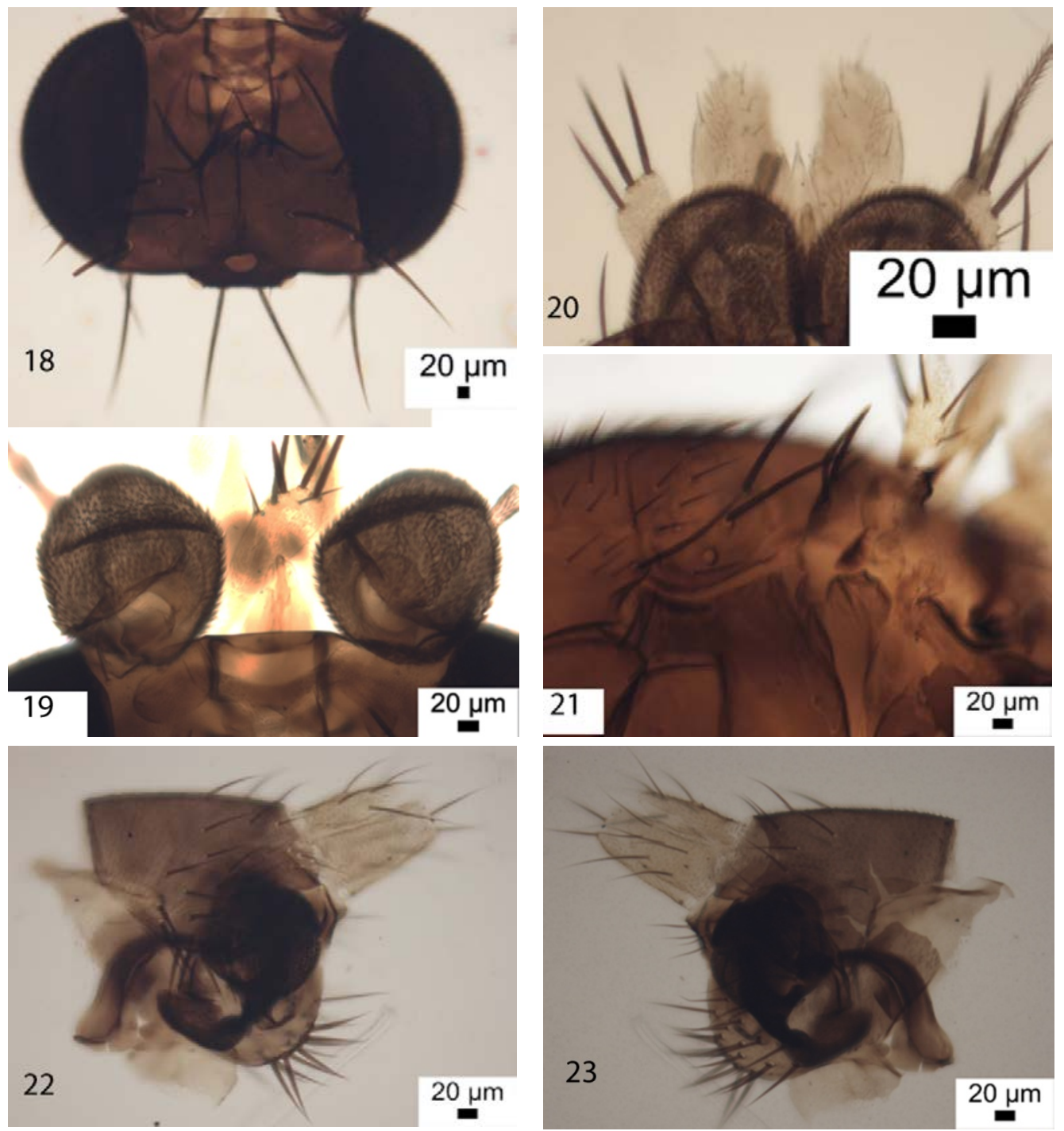
notopleuron; 22-23 - hypopygium.

Fore tarsus with posterodorsal hair palisade on segments 1-3 only (Fig. 24). Dorsal hair palisade of mid tibia extends about 0.6 times its length. Hind femur and tibia as Fig. 25. Hind tibia with up to 24 only moderately differentiated posterodorsal hairs, without anterodorsals, and spinules of apical combs simple. Wings (Figs 26 \& 27) 2.0-2.2 mm long. Costal index 0.52 . Costal ratios $2.0: 0.9: 1$. Costal cilia (of section 3) $0.07 \mathrm{~mm}$ long. No hair at base of vein 3. With 2 unequal axillary bristles, the outer be $0.13 \mathrm{~mm}$ long. Haltere knob pale gray.

Material examined. Holotype male, Finland, Lkor: Savukoski, Ainijärvi 7522293:3603111, 31 Jul-28 Sep 2015, J. Salmela leg. (Malaise trap) (UCMZ, 34-190). Paratype male as holotype.

Etymology. From horrentis (bristly) and cauda (tail) referring to epandrium. 

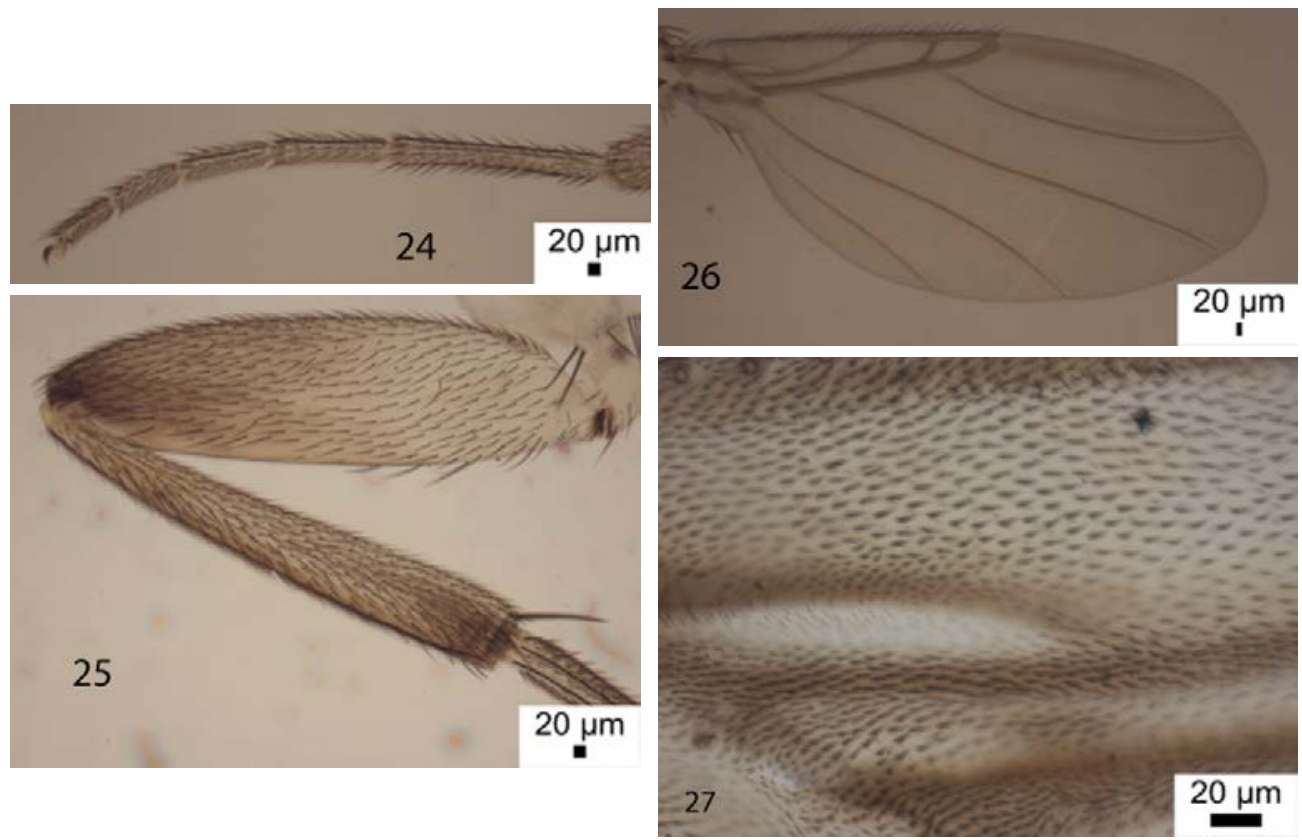

Figs 24-27. Megaselia horrenticauda n. sp. male: 24 - front tarsus; 25 - hind femur and tibia; 26 - wing; 27 subcosta.

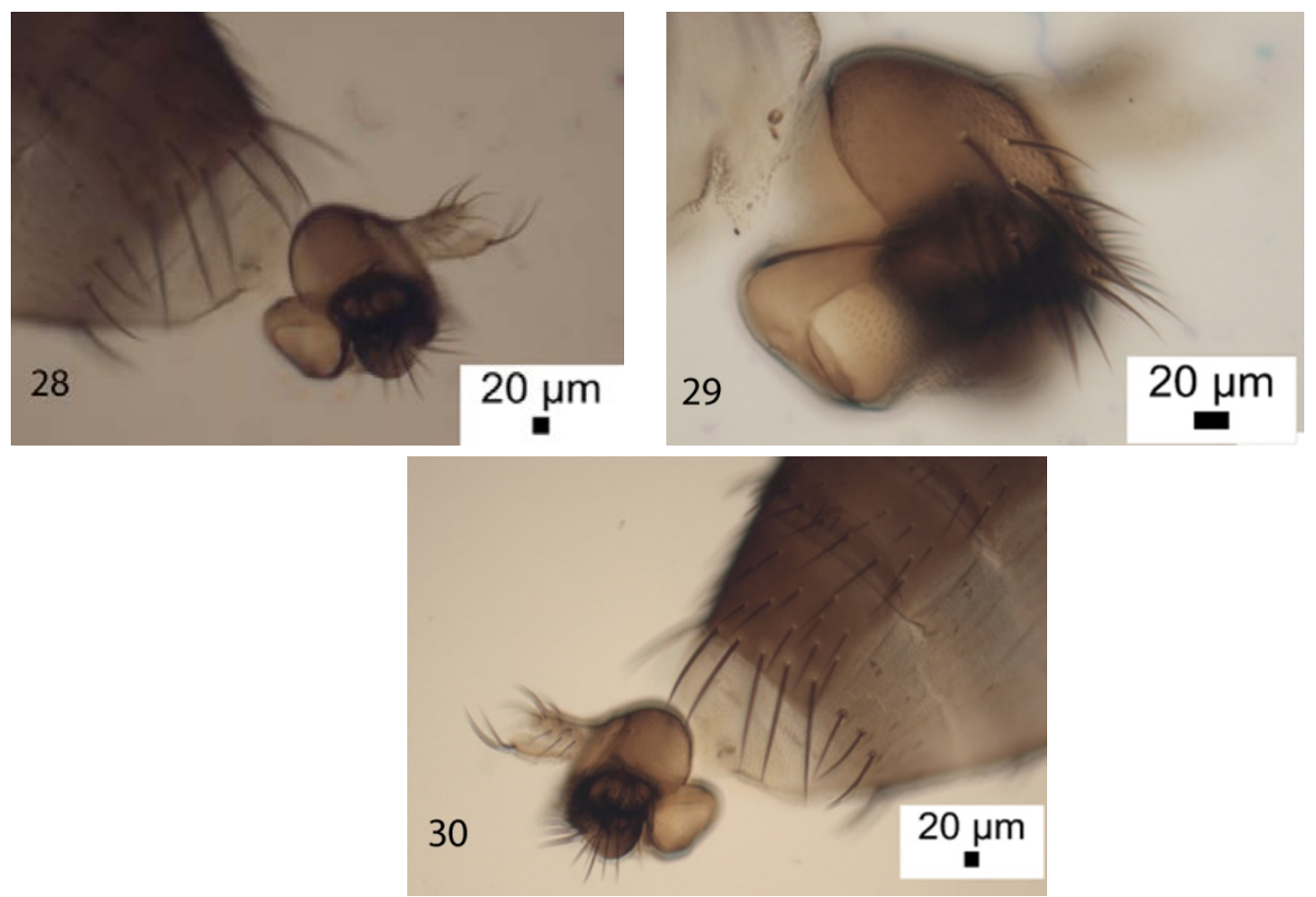

Figs 28-30. Megaselia spinicincta (Wood) male: 28-30 - hypopygium. 

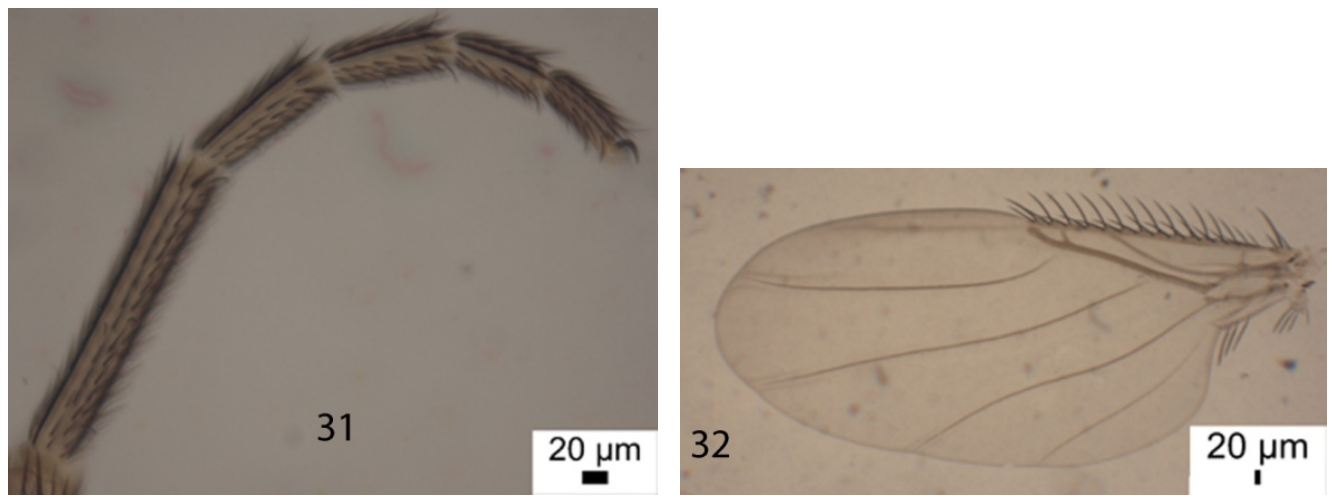

Figs 31-32. Megaselia spinicincta (Wood) male: 31 - front tarsus; 32 - wing.

\section{Megaselia kajaaniensis n. sp.}

(Figs 33-41)

Diagnosis (male). In Schmitz's (1957) key to Abteilung II species it runs to couplets 20 and 21 on page 432. M. intonsa Schmitz is immediately distinguished by its lack of hairs on segments 3 and 4 of the abdominal venter and its costal index being clearly less than 0.5 . M. palmeni (Becker) also lacks hairs on segments 3 and 4 of the venter and has fewer bristles on the epandrium. The other three species are readily distinguished by their very different hypopygia. In the key to British species (Disney 1989) it runs to couplet 55, lead 1 to M. palmeni.

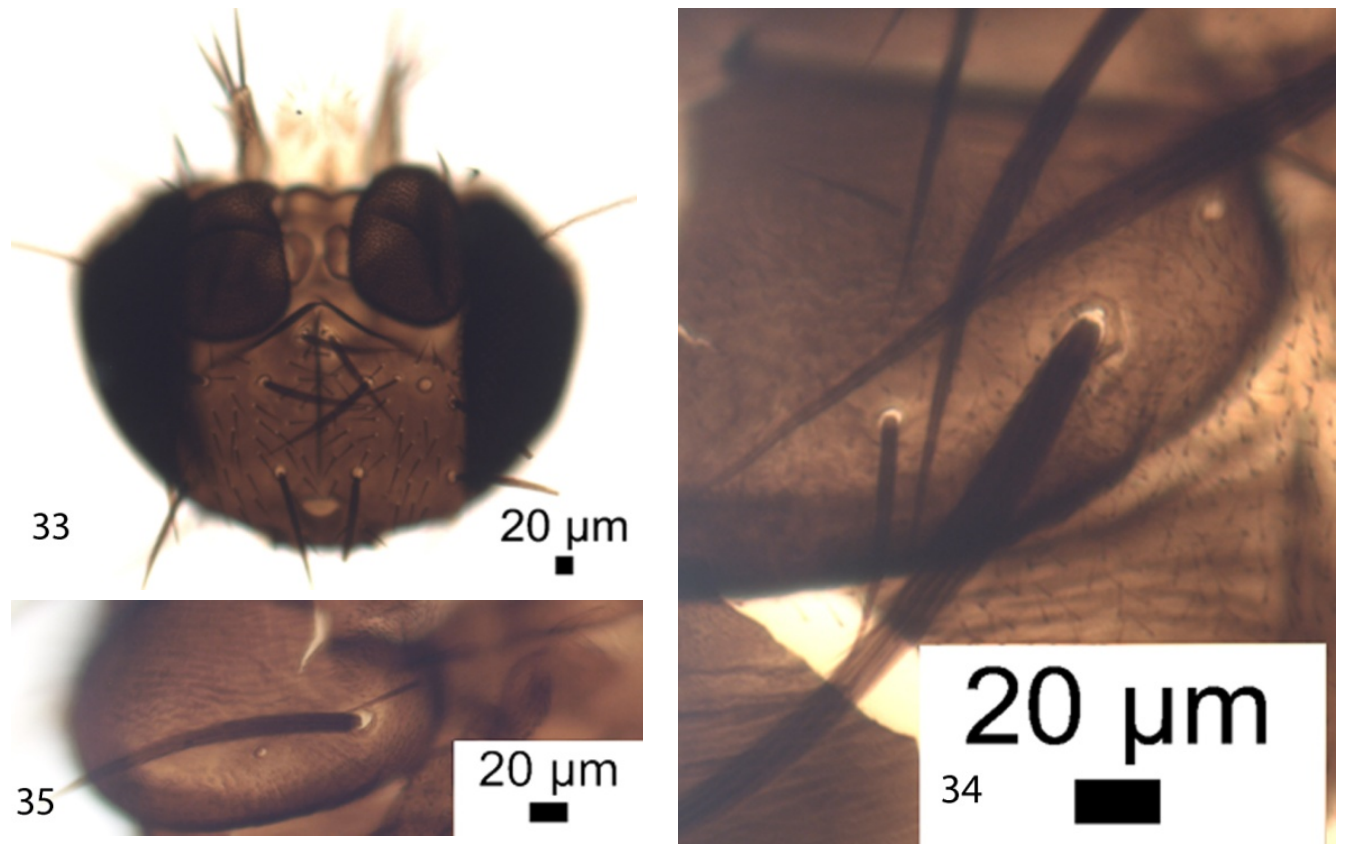

Figs 33-35. Megaselia kajaaniensis n. sp. male: 33 - head; 34-35 - scutellum. 

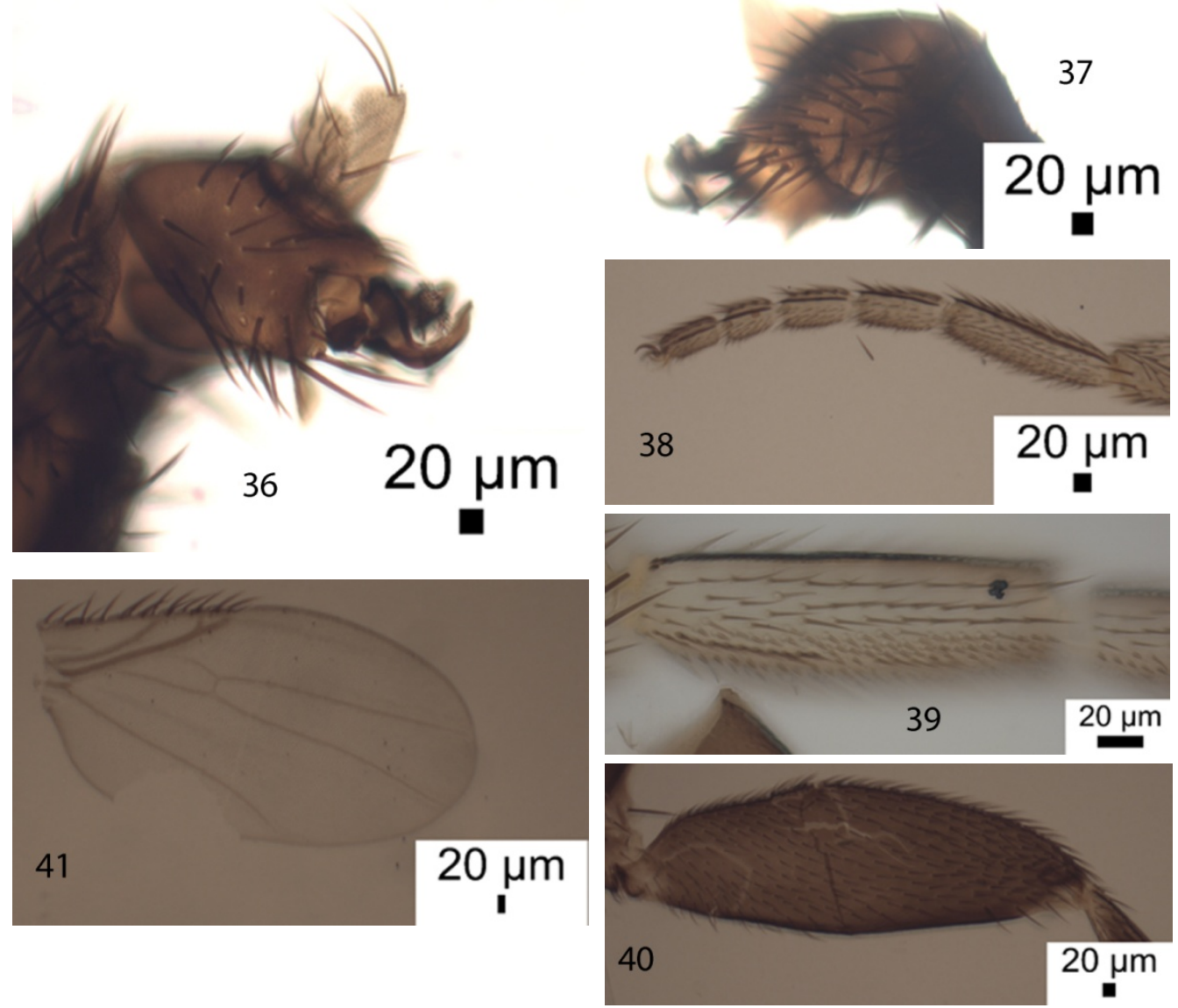

Figs 36-41. Megaselia kajaaniensis n. sp. male: 36-37 - hypopygium; 38 - front tarsus, 39 - basitarsus of front tarsus; 40 - hind femur; 41 - right wing of paratype.

Male. Head as Fig. 33, with dense but very fine microtrichia. Cheek with 5 bristles and jowl with two that are longer and more robust. Postpedicels without SPS vesicles. Palps pale brown or darker, with 6 bristles, a dozen hairs and small circular pits on their outer faces. Labrum pale and small. Labella pale and lacking short spinules below. Thorax brown. Three notopleural bristles and no cleft in front of these. Mesopleuron with 5-7 hairs and a bristle. Scutellum with an anterior pair of hairs, a posterior pair of bristles and a pair of small hairs (Figs 34-35). Abdominal tergites brown with numerous hairs that are longest at the rear of T6. Venter brown and with hairs on segments 3-6. Hypopygium as Figs 36-37. Middle and hind legs brown. Front legs, apart from brown bases to coxae, yellow. Fore tarsus as Fig. 38, with the basitarsus as Fig. 39. Dorsal hair palisade of mid tibia extends about 0.65 times its length. Hind femur as Fig. 40. Hind tibia with a dozen moderately differentiated posterodorsal hairs, without anterodorsals, and spinules of apical combs simple. Wings $1.3-1.6 \mathrm{~mm}$ long. Right wing of paratype as Fig. 41 but left wing lacks the cross vein linking veins 4 and 5 (as in normal phorid wings). Vein 7 not evident. Costal index 0.45-0.53. Costal ratios 3.5-4.2 : 1.31.4 : 1. Costal cilia (of section 3) $0.10 \mathrm{~mm}$ long. No hair at base of vein 3 . With 3 axillary bristles, the outer being $0.12 \mathrm{~mm}$ long. Sc not reaching R1. Haltere brown. 
Material examined. Holotype male, Finland, Ok: Kajaani, Otanmäki, 21 Jul 2015, 71086:35050, K. Winqvist leg. (UCMZ, 34-186). Paratype male, Ok: Kajaani, Pirttikangas, 71076:35052, 22 Jul 2015, K. Winqvist leg. (UCMZ, 34-188).

Etymology. Named after the type locality.

Comment. The cross vein in one wing of the paratype is a further case of a mutation restoring a plesiomorphic state (cf Disney 1985, 1991).

\section{Megaselia miroparaphysis n. sp.}

(Figs 42-51)

Diagnosis (male). In the keys to British species (Disney 1989) it runs to couplets 80 or 87, but its hypopygium differs from the species of these couplets and subsequently described species, as well as by other details. The hypopygium of $M$. nigripalpis (Lundbeck) was not illustrated but (as its name indicates) it has dark palps. In the keys of Schmitz \& Beyer (1965) it runs to couplet 15 on page 521 to M. sepulchralis (Lundbeck), which differs in having dark palps, legs and the anal tube of its different hypopygium. With its costal index of 0.44 the new species also needs to be run through the key of Schmitz \& Delage (1974), where it runs to couplets 32 and 36 on page 640 . Its hypopygium differs from the species of these couplets.
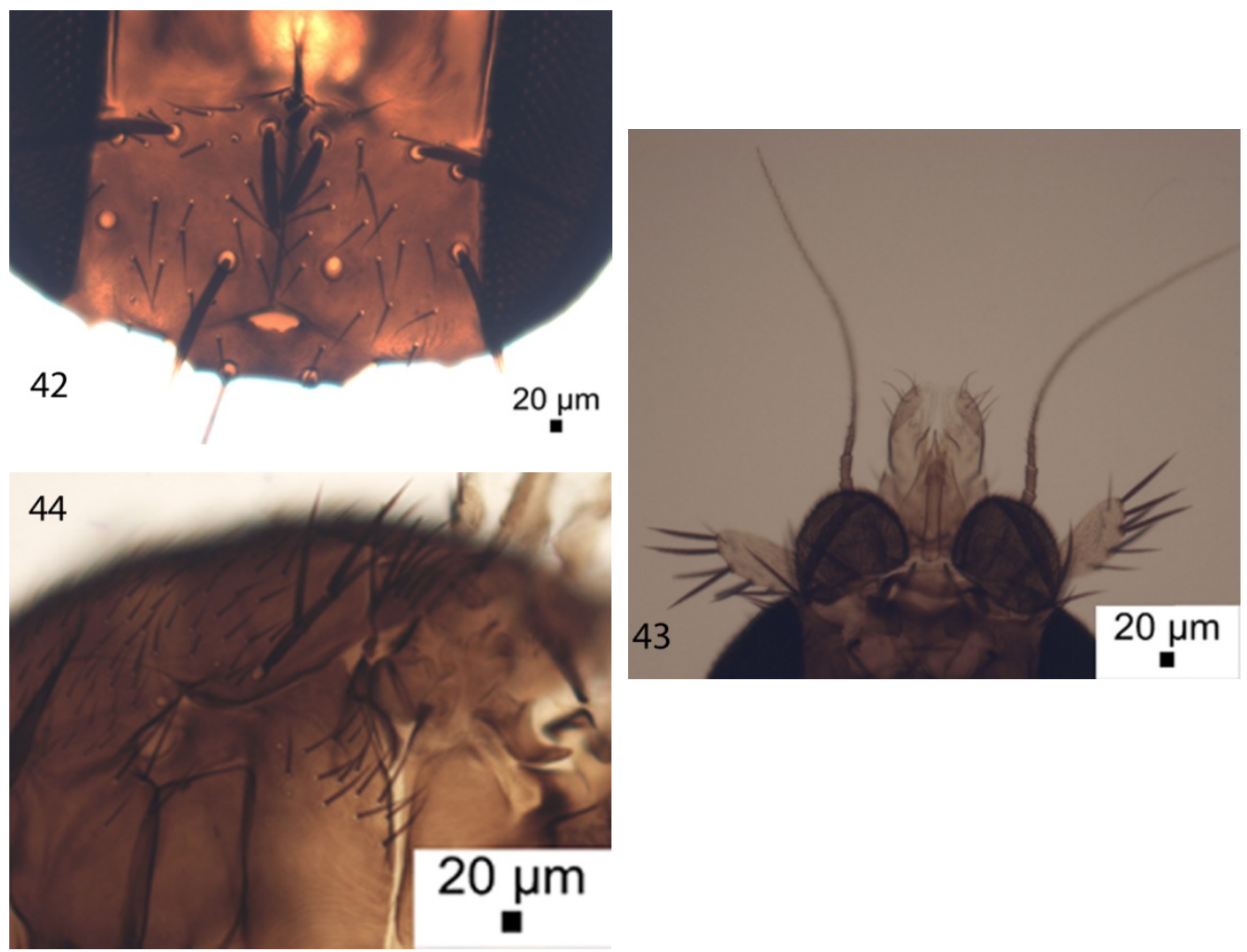

Figs 42-44. Megaselia miroparaphysis n. sp. male: 42 - frons; 43 - postpedicels, palps and proboscis; 44 - left face of thorax. 


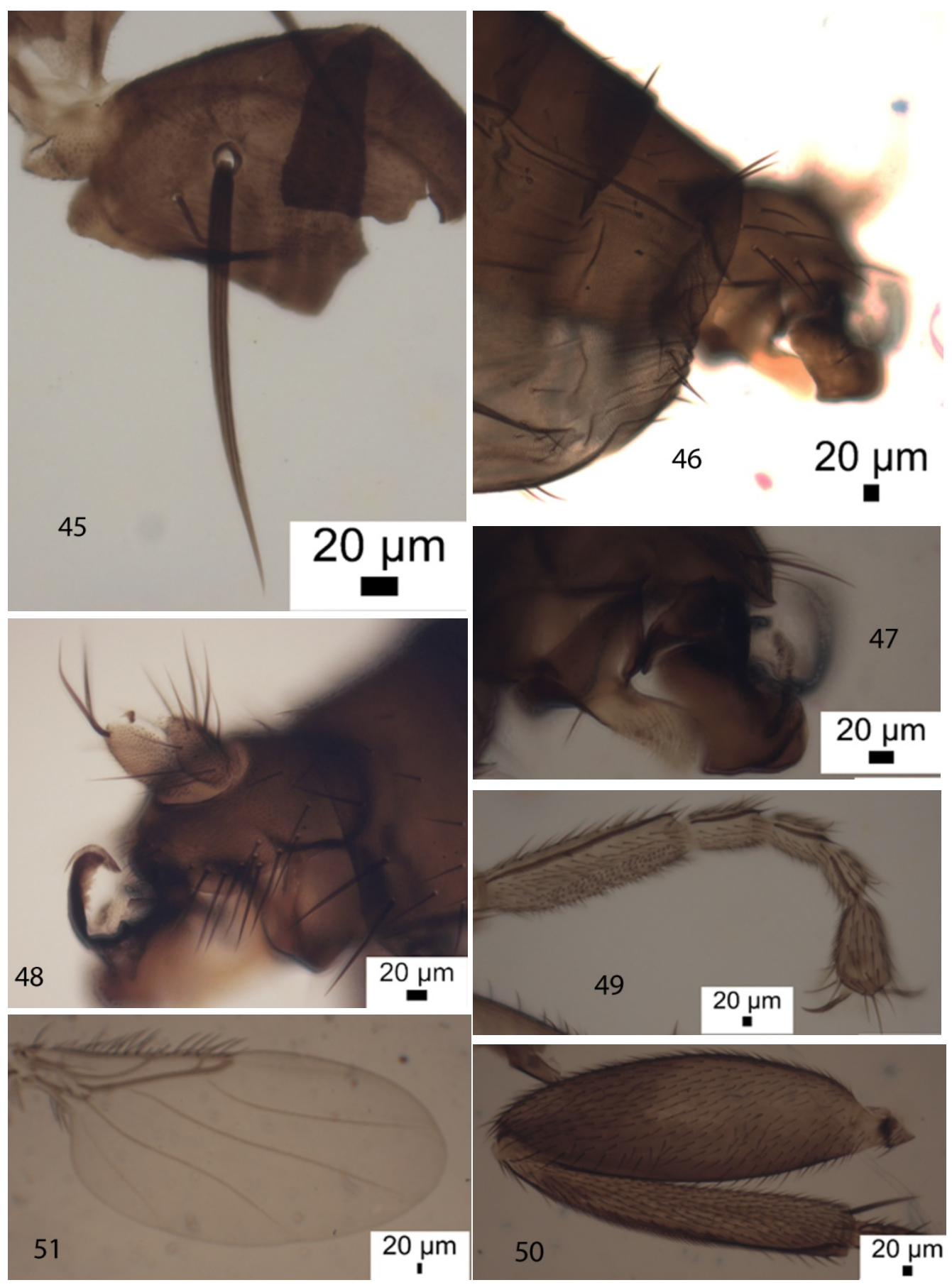

Figs 45-51. Megaselia miroparaphysis n. sp. male: 45 - scutellum; 46-48 - hypopygium; 49 - front tarsus; 50 - hind femur and tibia; 51 - wing. 
Male. Frons as Fig. 42 and with dense but very fine microtrichia. Postpedicels, palps and proboscis as Fig. 43, the postpedicels being without SPS vesicles. Thorax brown, with three notopleural bristles and no cleft in front of these, and mesopleuron with hairs (Fig. 44). Scutellum with an anterior pair of hairs, a posterior pair of bristles and a posterior pair of hairs (Fig. 45). Abdominal tergites brown with hairs mainly at hind margins. Venter gray, and with hairs on segments 3-6. Hypopygium as Figs 46-48. Middle and hind legs brown but front legs yellowish brown or paler in part. Fore tarsus as Fig. 49. Dorsal hair palisade of mid tibia extends about 0.6 times its length. Hind femur and tibia as Fig. 50, the tibia with 14-15 differentiated posterodorsal hairs, without anterodorsals, and spinules of apical combs simple. Wings (Fig. 51) $2.0 \mathrm{~mm}$ long. Costal index 0.44. Costal ratios $3.9: 2.4$ : 1. Costal cilia (of section 3) $0.16 \mathrm{~mm}$ long. A small hair at base of vein 3. With 3 axillary bristles, the outer being $0.14 \mathrm{~mm}$ long. Sc not reaching R1. Haltere brown.

Material examined. Holotype male, Finland, Lkor: Savukoski, Ainijärvi 7522397:3602914, 31 Jul-29 Sep 2015, J. Salmela leg. (Malaise trap) (UCMZ, 34-189).

Etymology. From miro (strange) with reference to the right paraphysis of the male hypopygium.

\section{Megaselia necrubida n. sp.}

(Figs 52-60)

Diagnosis (male). In the keys to British species (Disney 1989) it runs to couplet 150, where neither lead fits. In Schmitz \& Delage's (1981) keys to Abteiling VI it runs to couplet 47 lead 2, to the male attributed to M. rubida (Schmitz) by Lundbeck (1922). The latter is immediately distinguished by its brownish abdominal venter, the brown tip to the hind femur and costal section 1 being about equal to sections $2+3$. M. rubida was described from the female only. Its description was amplified by Buck \& Disney (2001). Its costal ratios correspond to those of Lundbeck's male.

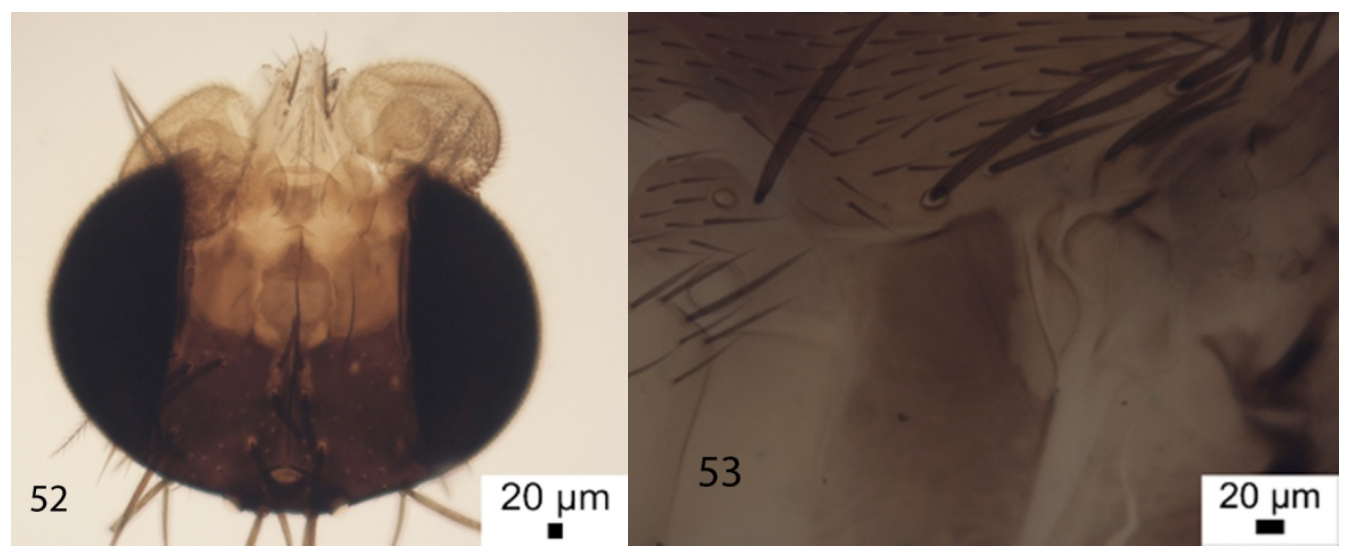

Figs 52-53. Megaselia necrubida n. sp. male: 52 - head; 53 - left face of thorax.

Male. (the abdomen was full of air bubbles whose expulsion caused some damage to the hypopygium). Head as Fig. 52, the frons having dense but very fine microtrichia. Palps yellow, with 6 bristles and fewer hairs. Labella narrow and pale. Thorax yellowish brown to brown. 


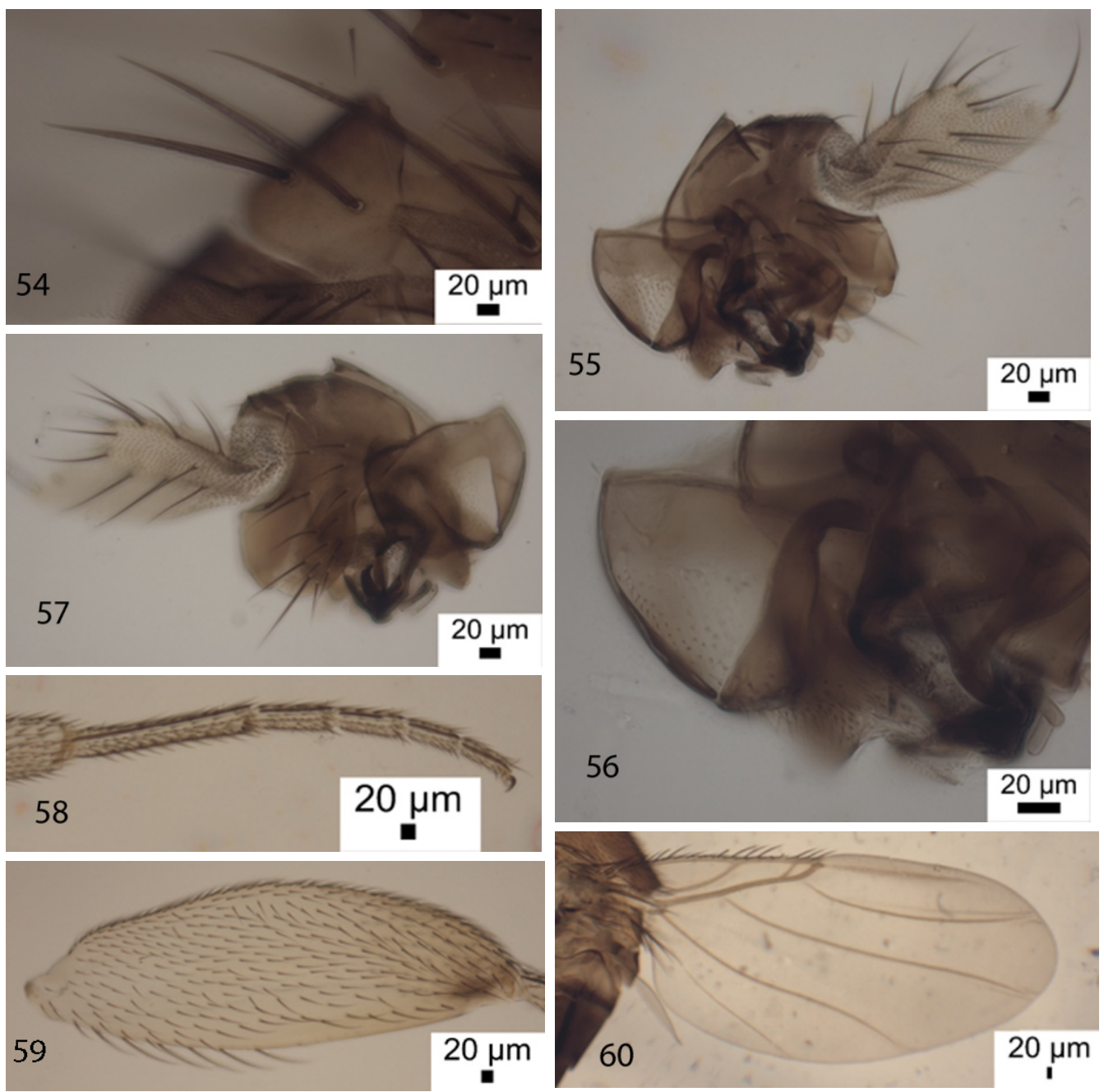

Figs 54-60. Megaselia necrubida n. sp. male: 54 - right side of scutellum; 55-57 - hypopygium; 58 - front tarsus; 59 - hind femur; 60 - wing.

The 3 notopleural bristles and bare mesopleuron as Fig. 53. Scutellum with 4 strong bristles (Fig. 54). Abdominal tergites brown with moderate hairs even at the rear of T6 (Fig. 55). Venter yellow and with hairs on segments 3-6. Hypopygium as Figs 55-57, with the left lobe of the hypandrium being pale and the right lobe vestigial. Legs yellow. Fore tarsus with posterodorsal hair palisade on segments $1-5$ and 5 longer than 4 (Fig. 58). Dorsal hair palisade of mid tibia extends about 0.9 times its length. Hind femur as Fig. 59. Hind tibia with a dozen differentiated posterodorsal hairs, without anterodorsals, and spinules of apical combs simple. Wing (Fig. 60) 1.8-1.9 mm long. Costal index 0.47. Costal ratios $5.1: 3.1-3.2: 1$. Costal cilia (of section 3) $0.10 \mathrm{~mm}$ long. No hair at base of vein 3 . With 3 axillary bristles, the outer being $0.12 \mathrm{~mm}$ long. Sc reaching R1. Haltere knob yellow.

Material examined. Holotype male, Finland, Ab: Turku, Satava, Samppa, 67015: 32387, mixed forest 9 Jul 2016, K. Winqvist leg. (14/16, UCMZ, 34-192).

Etymology. Named after its resemblance to Megaselia rubida. 


\section{Megaselia simulans (Wood, 1912)}

Previously known from British Isles, Ireland, and mainland Europe: from Sweden and Finland to Germany and Italy, Romania, Spain, and east to Russia west of the Urals. The following is the first record for Finland:

Material examined. Male, Finland, Ab: Mynämäki, Karjalankylä, 13 Sep-20 Nov 2012, 67568:32279, E. Vesterinen leg. (hybrid trap).

\section{Megaselia turkuensis n. sp.}

(Figs 61-70)

Diagnosis (male). In the keys to British species (Disney1989) it runs to couplet 260. If one ignores the first part of lead 1 then one is returned to couplet 156 . This is the section revised by Buck \&Disney (2001), in whose key to males it runs to couplet 2, where neither option applies. However, a note suggests that the unknown male of $M$. septentrionalis (Schmitz) might run to this couplet, but it has a yellow haltere knob in contrast to the new species. M. turkuensis fails to run down in Borgmeier's (1966) relevant keys to Nearctic species.

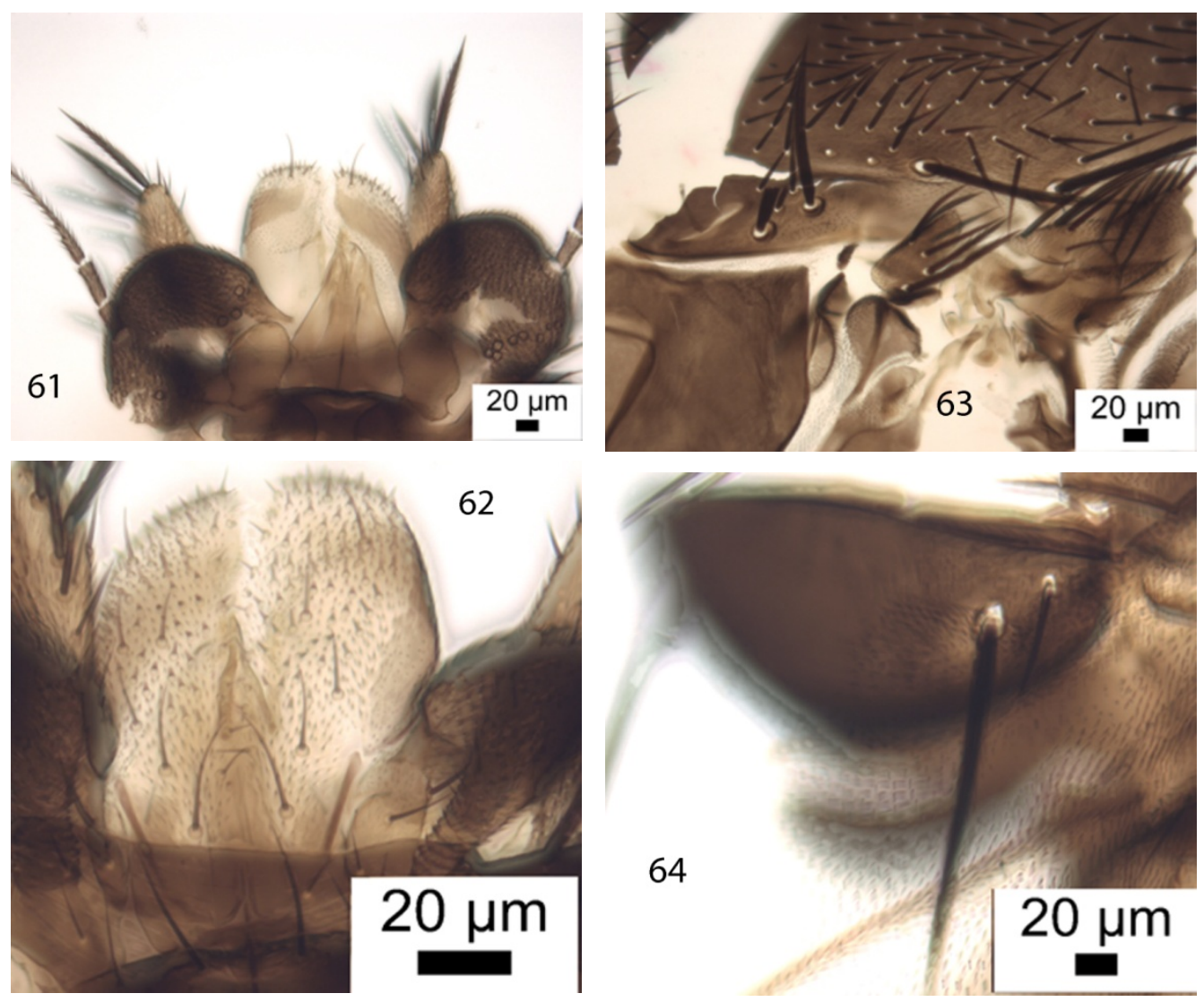

Figs 61-64. Megaselia turkuensis n. sp. male: 61 - postpedicels (ruptured), palps a proboscis; 62 - labellum from below; 63 - notopleuron with cleft; 64 - right side of scutellum. 

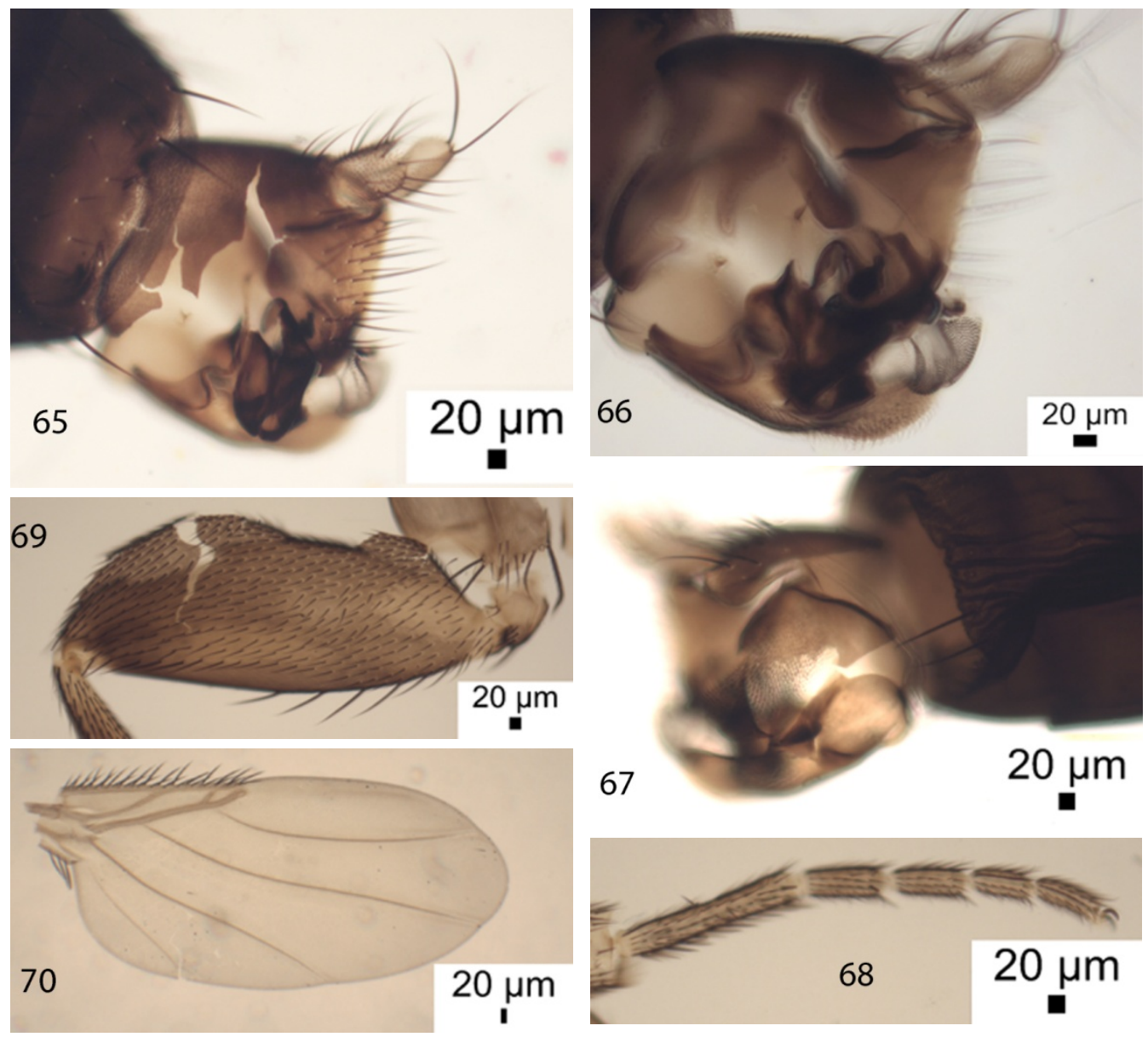

Figs 65-70. Megaselia turkuensis n. sp. male: 65-67 - hypopygium; 68 - front tarsus; 69 - hind femur; 70 -wing.

Male. (with damaged head and hypopygium). Frons brown, clearly broader than long, with 60-70 hairs and dense but very fine microtrichia. SAs robust but lower pair shorter. The antials lower on frons than anterolaterals, and about as far from upper SAs as either is from an AL bristle. Pre-ocellars further apart than upper SAs but about equidistant from each other and as either is from a mediolateral bristle, which is about the same level on frons. Cheek with 5 bristles and jowl with a longer one. Postpedicels with SPS vesicles (Fig. 61). Palps and proboscis as Fig. 61, with the lower faces of labella as Fig. 62. Thorax brown. Two notopleural bristles and a cleft in front of these (Fig. 63). Mesopleuron bare (Fig. 63). Scutellum with an anterior pair of hairs and a posterior pair of bristles (Fig. 64). Abdominal tergites brown with numerous hairs that are longest at the rear of T6. Venter brown, and with hairs on segments 3-6. Hypopygium as Figs 65-67. Legs brown but parts of front legs yellowish brown or paler. Fore tarsus as Fig. 68. Dorsal hair palisade of mid tibia extends about 0.8 times its length. Hind femur as Fig. 69. Hind tibia with a dozen moderately differentiated posterodorsal hairs and a longer pre-apical, without anterodorsals, and spinules of apical combs simple. Wings (Fig. 70) 1.6 mm long. Costal index 0.44. Costal ratios 3.4 : 
2.0-2.1 : 1. Costal cilia (of section 3) $0.09 \mathrm{~mm}$ long. Hair at base of vein 3 small. With 3 axillary bristles, the outer being $0.11 \mathrm{~mm}$ long. Sc not reaching R1. Haltere brown.

Material examined. Holotype male, Finland, Ab: Turku, Ilpoinen, 67081:32404, 3 Jun 2014, K. WinqvisT (UCMZ, 34-163).

Etymology. From the type locality of the holotype.

\section{Megaselia utsjokiensis n. sp.}

(Figs 71-80)

Diagnosis (male). In the keys to British species (Disney 1989) it runs to couplet 275, lead 1 to $M$. cinerea Schmitz. It is immediately distinguished by having 3, not 2, bristles on the notopleuron, numerous SPS vesicles in the postpedicel and a much longer labrum.

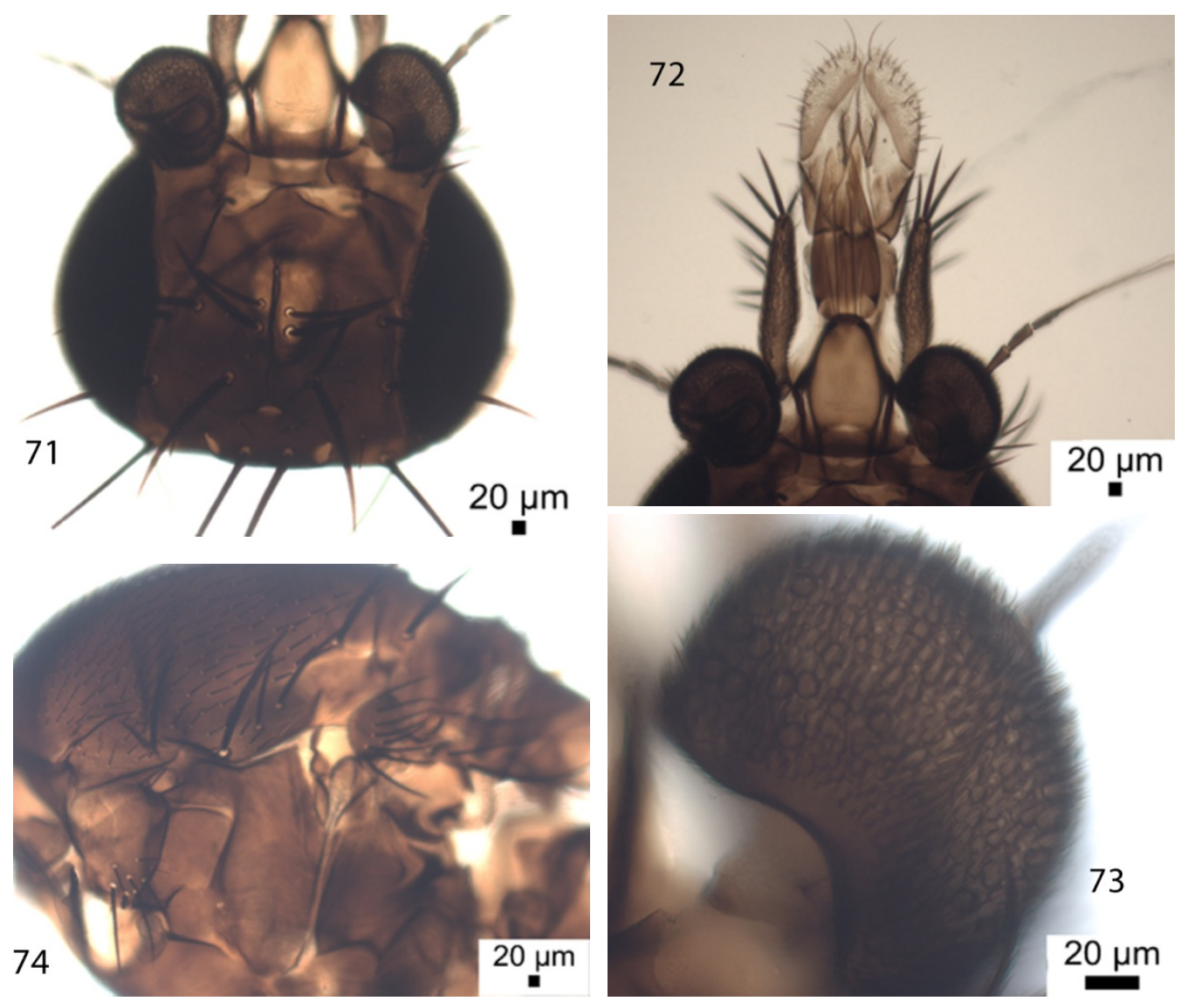

Figs 71-74. Megaselia utsjokiensis n. sp. male: 71 - frons and postpedicels; 72 - postpedicelds, palps and proboscis; 73 - postpedicel showing SPS vesicles; 74 - left face of thorax.

Male. Frons as Fig. 71 and with dense but very fine microtrichia. Cheek with 4 bristles and jowl with two that are much longer and more robust. Postpedicels with SPS vesicles (Fig. 73). Palps and proboscis as Fig. 72. Thorax brown. Three notopleural bristles, the middle one being shorter that the other two (Fig. 74). Mesopleuron bare (Fig. 74). Scutellum with an anterior pair of hairs and a posterior pair of bristles. Abdominal tergites brown with numerous hairs that are 
longest at the rear of T6. Venter gray, and with hairs on segments 3-6. Hypopygium as Figs 7577. Legs brown but parts of front legs yellowish brown or paler. Fore tarsus as Fig. 78. Dorsal hair palisade of mid tibia extends about 0.5-0.6 times its length. Hind femur as Fig. 79. Hind tibia with about two dozen weakly differentiated posterodorsal hairs, without anterodorsals, and spinules of apical combs simple. Wings (Fig. 80) $2.43 \mathrm{~mm}$ long. Costal index 0.52. Costal ratios 3.2 : 1.5-1.6 : 1. Costal cilia (of section 3 ) $0.17 \mathrm{~mm}$ long. Hair at base of vein 3 minute. With 5 axillary bristles, the outer being $0.19 \mathrm{~mm}$ long. Sc reaching R1. Haltere brown.

Material examined. Holotype male, Finland, LI: Utsjoki, Galddasjohka, 7764156: 3536707, 13 Jul-25 Aug 2016, J. Salmela leg. (Malaise trap) (5/16, (UCMZ, 39-83).

Etymology. From the type locality of the holotype.
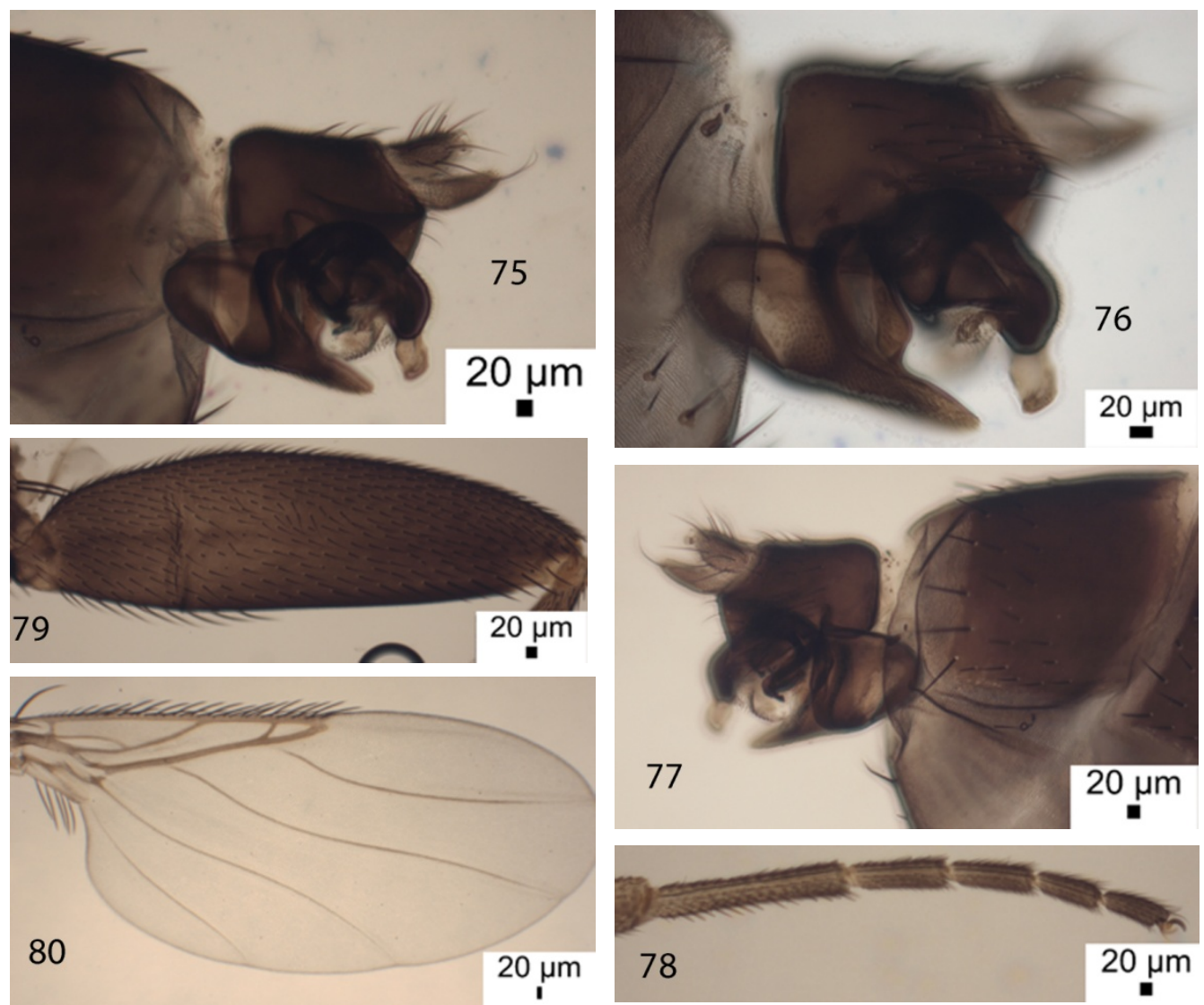

Figs 75-80. Megaselia utsjokiensis n. sp. male: 75-77 - hypopygium; 78 - front tarsus; 79 - hind femur; 80 - wing.

\section{Megaselia wigtownensis Disney, 2009}

This is the first record for Finland. Previously known from Scotland and Spain.

Material examined. Male, Finland, Obb: Tervola, Pisavaara, Alalaki, 7348763: 3414247, mossy spring area, 8 Jul-15 Aug 2016, J. Salmela leg. (Malaise trap). 
Triphleba aequalis (Schmitz, 1919)

(Figs 81-84)

Trupheoneura aequalis Schmitz, 1929: 189 (male).

The hitherto unknown female is described below.

In the key of Schmitz (1943) it runs to couplet 57, lead 1 to T. excisa. However, its female sternite 7 has much shorter posterolateral processes (Fig.168 in Disney 1983). The subsequently described T. bifida Schmitz (1949) runs to the same point in the key and its sternite 7 closely resembles that of $T$. aequalis but with shorter posterolateral processes (Fig. 85). In addition Schmitz gave its wing length as $2.79 \mathrm{~mm}$, its costal index as 0.55 and its costal ratios as $1.65: 1.35: 1$. For the females of $T$. aequalis reported below these measurements differ a little (see below). It is possible that Schmitz's measurements represent small extensions of the ranges for $T$. aequalis and that the shorter posterolateral processes of sternite 7 in T. bifida as figured by Schmitz (Fig. 85) represent a foreshortening due to the tilt of a pinned specimen. If so then $T$. bifida would become a synonym of $T$. aequalis.
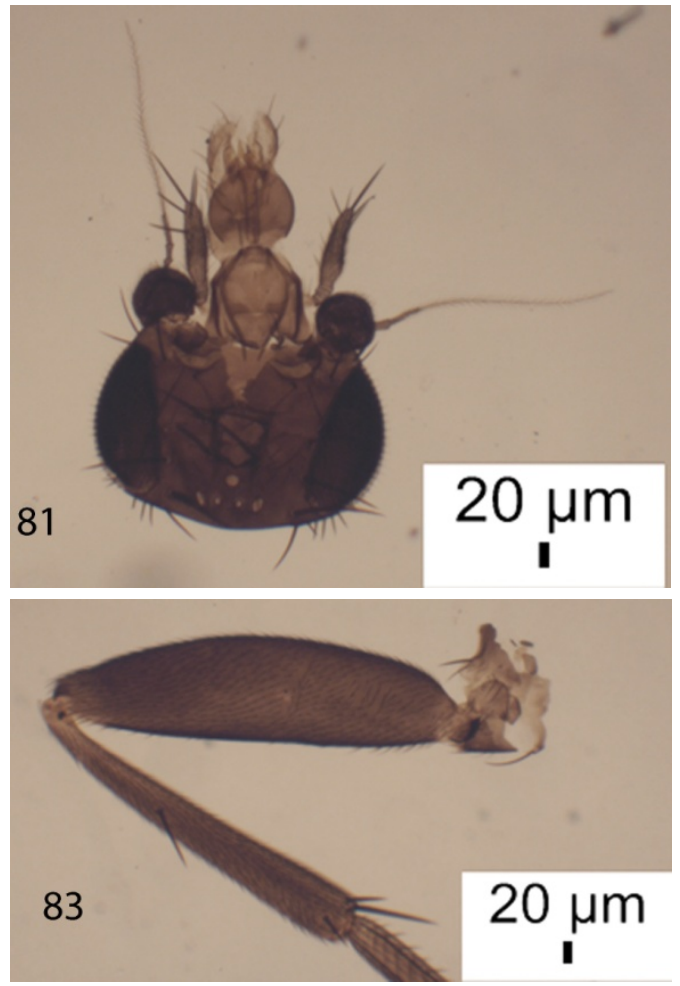
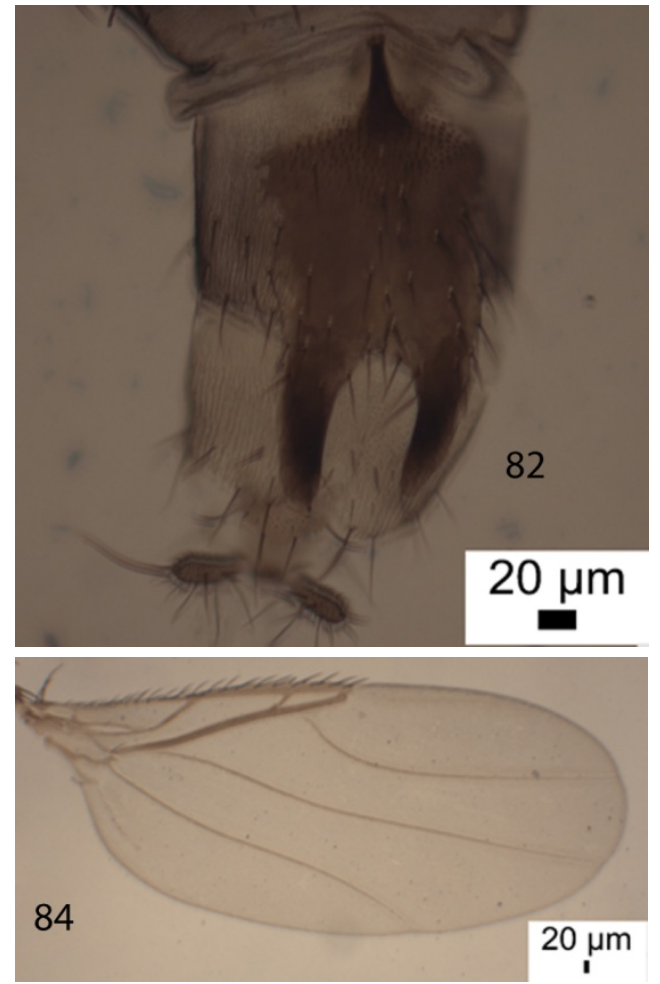

Figs 81-84. Triphleba aequalis female: 81 - head; 82 -sternite 7; 83 - hind femur; 84 - wing.

Female. Head as Fig. 81. Abdominal tergites 1-6 brown with moderate hairs. T6 longer than T5 and slightly tapered and T7 represented by hairs only. Sternite 7 as Fig. 82. Hind femur and tibia as Fig. 83. Wing (Fig. 84) 2.11-2.26 mm long. Costal index 0.50-0.54. Costal ratios $1.72-2.13: 1.44-1.68: 1$.

Previously Known from Austria, Czech Republic, Denmark, France, Germany, Hungary, Italy, Poland, Spain, Sweden. 
Material examined. 2 males, 4 females, Finland: Lkor: Savukoski, Ainijärvi 7522397:3602914 and 7522293:360311, 30 Jul-28 Sep 2015, J. Salmela leg. (Malaise trap) (UCMZ, 34-187, 189).

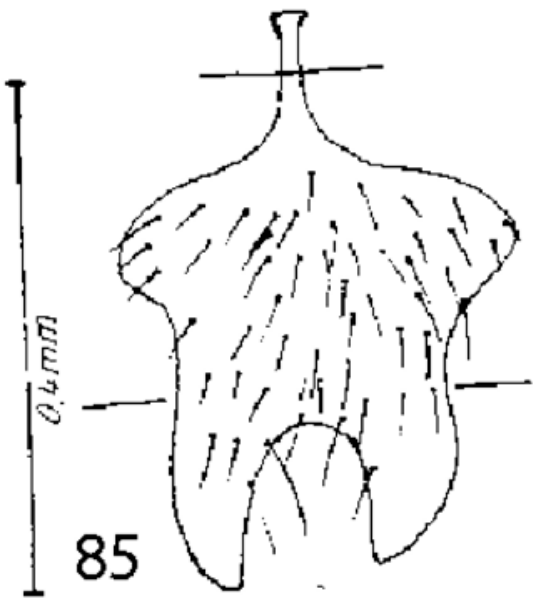

Fig. 85. Triphleba bifida Schmitz, female sternite 7 (from Schmitz, 1949).

\section{Triphleba cumsetae n. sp.}

(Figs 86-91)

Diagnosis. In the key of Schmitz (1943) it runs to couplet 61 on page 144. The lack of sternite 7 distinguishes $T$. distinguenda (Strobl) although its tergites 5 and 6 are similar (Fig. 92) and even more so in a teneral specimen (Fig. 93). It is possible, therefore that the holotype of $T$. cumsetae is teneral. The other species of couplet 61 is the Hungarian T. longifurcata (Schmitz), whose female is unknown. It is possible that $T$. cumsetae is a teneral specimen of T. longifurcata, but Schmitz's description of vein 3 makes no reference to a row of hairs before the fork (see below).
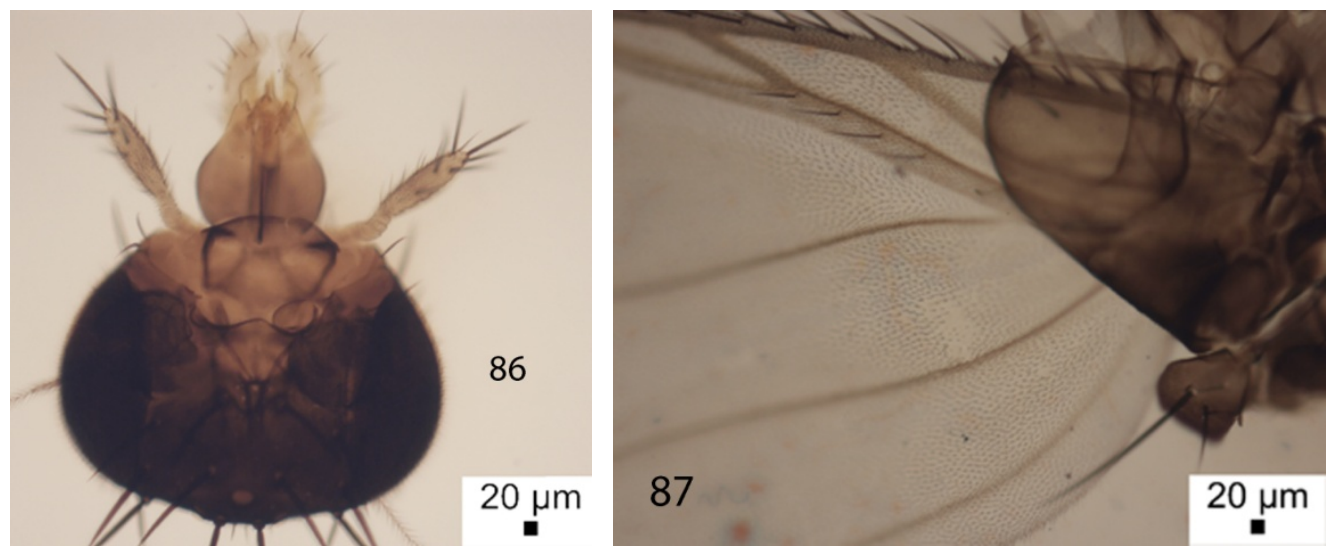

Figs 86-87. Triphleba cumsetae n. sp. female: 86 - head; 87 - scutellum and hairs before fork on vein 3. 
Female. Head as Fig. 86. Notopleuron with 3 bristles, the most anterior being the longest and the most posterior the shortest. Scutellum as Fig. 87. Abdominal tergites light brown (Fig. 88), with T7 represented by hairs only. Venter brownish gray with hairs on segments 3 to 6 , with the longest at the rear of segment 6. Sternite 7 as Fig. 89. Legs brown. Hind femur and tibia as Fig. 90. Wing (Fig. 91) 2.24-2.25 mm long. Costal index 0.48. Costal ratios $1.8: 1.3$ : 1. Costal cilia (of section 3) $0.09 \mathrm{~mm}$ long. The single axillary bristle $0.14 \mathrm{~mm}$ long. The hair at base of vein 3 is $0.16 \mathrm{~mm}$ long; and with a row of smaller hairs before the fork (Fig. 87). Haltere brown.

Material examined. Holotype female, Finland, Ab: Turku, Pahaniemi, 67115:32365, 5 Sep 2014, margin of wood, K. Winqvist (UCMZ, 34-164).

Etymology. From cum (with) setae (hairs), referring to the hair on vein 3 in addition to the bristle at its base.
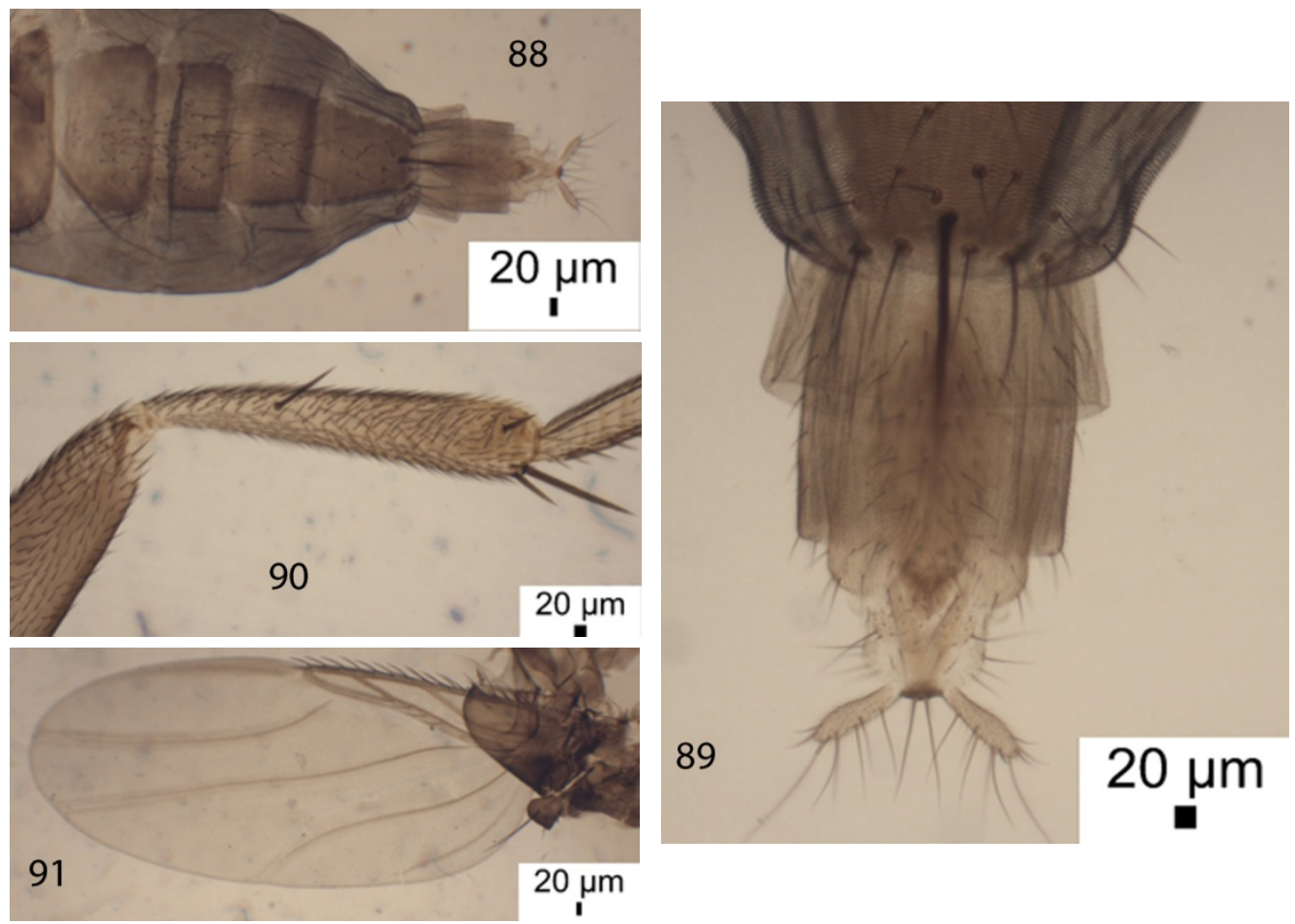

Figs 88-91. Triphleba cumsetae n. sp. female: 88 - abdominal tergites 3-6; 89 - sternite 7; 90 - tip of hind femur and tibia; 91 - wing.

\section{Triphleba papillata (Wingate, 1906)}

Previously known from British Isles, Mainland Europe: from Norway and Sweden to Austria, Belgium, Denmark, France, Germany, Poland to Switzerland, The Netherlands, Italy and Spain, and east to the Czech Republic, Hungary and Slovakia. The following is the first recorded specimens for Finland.

Material examined. 2 males, Finland, Ab: Turku, Satava, Tammivalkama, 67034:32368, 4 Apr 2016, margin of a little oak wood, K. Winqvist leg., Ab: Turku, Satava, Hennala 67027:32355, 4 Apr 2016, dry meadow, K. Winqvist, K. Winqvist \& A. Haarto det. 

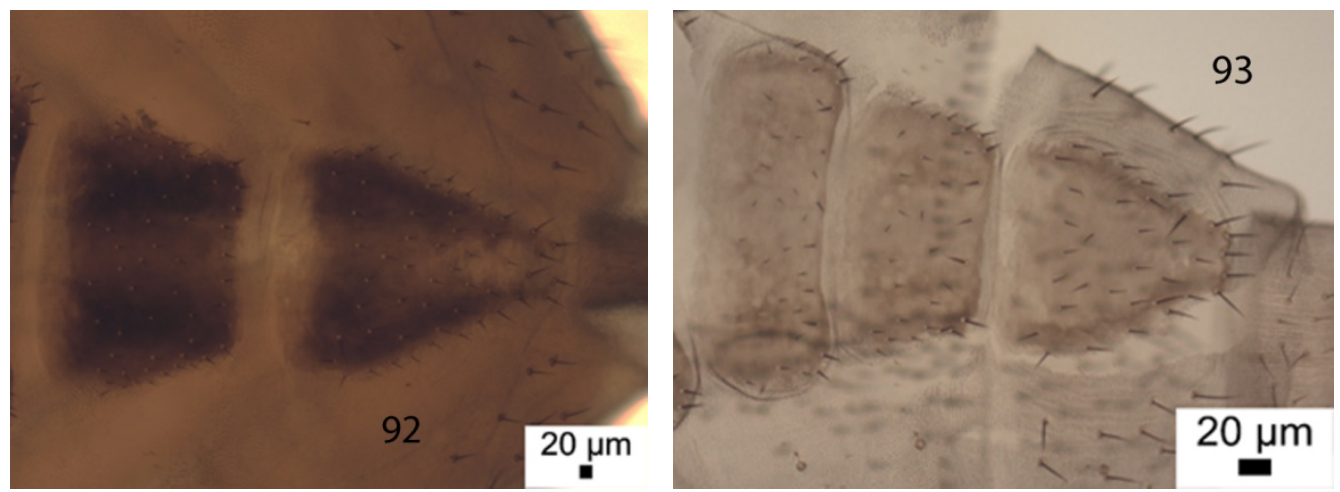

Figs 92-93. Triphleba distinguenda female: 92 - abdominal tergites 5 and 6; 93 - T5 \& T6 of a teneral specimen.

\section{DISCUSSION}

It is evident that the list of Phoridae recorded from Finland is still far from complete, especially for the genus Megaselia. However, our records make the numbers recorded more in line with those reported from Norway and Sweden. In addition there are a number of females of this huge genus that cannot be named until linked to their males.

\section{ACKNOWLEDGEMENTS}

RHLD's studies of Phoridae are currently supported by a grant from the Balfour-Browne Trust Fund (University of Cambridge).

\section{REFERENCES}

Borgmeier T. 1964. Revision of the North American Phorid flies. Part II. The species of the genus Megaselia, subgenus Aphiochaeta (Diptera, Phoridae). Studia Entomologica, Petropolis 7: 257-416.

Borgmeier T. 1966 (1965). The species of the genus Megaselia, subgenus Megaselia (Diptera, Phoridae). Studia Entomologica, Petropolis 8: 1-160.

BuCK M. \& Disney R. H. L. 2001. Revision of the Megaselia giraudii and M. densior species complexes of Europe, including ecological notes (Diptera, Phoridae). Beiträge zur Entomologie 51: 73-154.

DisNEY R. H. L. 1983. Scuttle Flies - Diptera, Phoridae (except Megaselia). Handbooks for the Identification of British Insects 10 (6): 1-81.

DiSNEY R. H. L. 1985. Re-interpretation of the wing veins in the Phoridae (Diptera). Entomologist's Monthly Magazine 121: 55-58.

Disney R. H. L. 1987. Rescue of Megaselia fenestralis (Diptera: Phoridae) from synonymy and its removal from British List. Entomologist's Gazette 38: 13.

Disney R. H. L. 1989. Scuttle Flies Diptera Phoridae Genus Megaselia. Handbooks for the Identification of British Insects 10 (8): 1-155.

DISNEY R. H. L. 1991. Support for the revised interpretation of the wing veins of Phoridae (Diptera). Entomologist's Monthly Magazine 127: 73-76.

DisNEY R. H. L. 2001. The preservation of small Diptera. Entomologist’s Monthly Magazine 137: 155-159.

DisNEY R. H. L. 2017. Systematic review of the European Gymnophora Macquart (Diptera: Phoridae), with five new species. Fragmenta Faunistica 60 (1): 23-46.

HACKMAN W. 1980. A check list of the Finnish Diptera I., Nematocera and Brachycera (s. str.) Notulae Entomologicae 60. 17-48.

KAHANPÄÄ J. 2014. Checklist of the families Lonchopteridae and Phoridae of Finland (Insecta Diptera). In: KAHANPÄÄ J. \& SALMElA J. (eds), Checklist of the Diptera of Finland. Zookeys 441: 213-223. doi.org/10.3897/zookeys.441.7197.

Schmitz H. 1929. Revision der Phoriden. Berlin: Ferd. Dummlers. 212 pp +Tafel I and II.

SchmitZ H. 1957. Phoridae. In: LindNeR E. (ed.), Die Fliegen der palaearktischen Region 4(33), (Lief. 196): 417464. Stuttgart, E. Schweizerbart'sche Verlagsbuchhandlung. 
Schmitz H. \& Delage A. 1974. Phoridae. In: Lindner E. (ed.), Die Fliegen der palaearktischen Region 4 (33) (Lieferung 301): 638-664. Stuttgart, E. Schweizerbart'sche Verlagsbuchhandlung.

Schmitz H. \& Delage A. 1981. Phoridae. In: Lindner E (ed.), Die Fliegen der palaearktischen Region 4(33) (Lieferung 325): 665-712. Stuttgart, E. Schweizerbart’sche Verlagsbuchhandlung.

\section{STRESZCZENIE}

[Nowe dane i opisy nowych gatunków z rodzaju Megaselia Rondani i Triphleba Rondani (Diptera: Phoridae) z Finlandii]

$\mathrm{Z}$ materiału Phoridae zebranego w Finlandii zostało opisanych osiem nowych dla nauki gatunków z rodzaju Megaselia: M. confusus n. sp., M. eeroi n. sp., M. horrenticauda n. sp., M. kajaaniensis n. sp., M. miroparaphysis n. sp., M. necrubida n. sp., M. turkuensis n. sp., M. utsjokiensis $\mathrm{n}$. sp. Ponadto, opisana została samica nowego dla nauki gatunku $\mathrm{z}$ rodzaju Triphleba: T. cumsetae n. sp. Przedstawiono również opis nieznanej dotychczas samicy gatunku T. aequalis. 